\title{
Two Cheers and a Pint of Worry: An On-Line Course in Political and Social Philosophy
}

\author{
Eugene F. Heath \\ Department of Philosophy, SUNY \\ 1000 JFT, New Paltz \\ NY 12561 \\ e-mail: HEATHE@npvm.newpaltz.edu
}

\begin{abstract}
Reprinted in the JALN with permission of the Teaching Philosophy; the original article appears in the Teaching Philosophy, Volume 20, 1997: Two Cheers and a Pint of Worry: On-Line Course in Political and Social Philosophy, Eugene Heath, at New Paltz
\end{abstract}

During the past decade there have been numerous efforts to reinvigorate distance education; some of these have involved video technology, but others have made use of computers and advances in the design of computer software. In 1995, the State University of New York, funded by a major grant from the Sloan Foundation, embarked upon the creation of an "on-line" learning program--a set of asynchronous and distance learning courses delivered solely via computer. In what follows, I detail the genesis and structure of a course in political and social philosophy that I designed (and taught) for this project. After some preliminary comments on the "virtual classroom" [1]. I illustrate the design of the course, and then offer a brief qualitative assessment. I close the essay with some cautionary reflections on computer-mediated education. Athough my initial skepticism about such courses has been modified, I still believe that there is something valuable about the direct, face-to-face, encounter of teacher and student that is not easily compensated for in computer-mediated learning.

\section{THE VIRTUAL CLASSROOM}

Although distance learning has traditionally involved correspondence, off-campus courses, or television and radio broadcasts, the idea of on-line (computerized) distance learning is not new; however, the technology is only now being exploited to any degree. Over the past few years, a variety of institutions--including New York University, Drexel University, New Jersey Institute of Technology, the New School, Mercy College, and Great Britain's Open University--have begun to offer various programs which are delivered wholly on-line. Such courses reach students who cannot attend classes on the home campus and are, therefore, distance learning courses; however, these courses are also asynchronous in that a student can participate on-line at any time of day or night.

The SUNY/Sloan initiative, now called the SUNY Learning Network (SLN), seeks to provide college courses and degree programs for working adults who, because of location or schedule, cannot attend traditional classes held on a university campus. As of this writing, the SLN (which is slated for expansion to other SUNY institutions) involves eight colleges in the Hudson River Valley--SUNY at New Paltz, Empire State College (a SUNY college dedicated to distance 
learning), and six community colleges; faculty are recruited from each of the affiliated institutions and the technical expertise is provided by the Center for Learning and Technology at Empire State College. Two distinct degree programs are being considered or developed: Under the direction of SUNY at New Paltz, a B.A. in Liberal Studies (focusing on issues of "Society and Public Life"), and under the guidance of Empire State College, a B.S. in Business, Management and Economics.

Since each course is delivered on-line, each student must have access to a personal computer (an IBM clone must have a 386 processor and Windows 3.1 or higher) equipped with a modem of at least 9600 baud, four megabytes of RAM, and 20 megabytes of free hard disk space [2]. The software for each course is Lotus Notes, a client/server "groupware" which allows for various databases which can include standard documents, conferences, e-mail, and the sorting and tracking of participant input. Each course is conducted without any face-to-face interaction: The professor and students each work from a personal computer and communicate with one another by replicating course databases to a server, a process which allows any changes to a user's database to be captured on the server and any changes on the server to be captured, in turn, on the user's database.

The course which I developed and taught (Fall semester, 1995) is an introductory course in political and social philosophy which focuses on the social contract tradition, specifically, Hobbes, Locke, and Rousseau. The initial enrollment in the course was eighteen students, six of whom were in-residence students at New Paltz who, lacking a personal computer in their dormitory rooms, were obliged to use the computer center at the college. The remainder of the students lived in the surrounding area and were able to work from a computer at home. Of the initial group of eighteen, ten would withdraw (officially) from the course. Of the eight survivors, only one was an in-residence student; the others were older than the typical college student, most were working full-time, and some were married with a family.

From the point at which I began to develop the course, I endeavored to ensure that the technology would not drive the content: Despite the fact that this course was to be on-line, it was my view that its content should not differ, in any significant manner, from that which a student would receive in a traditional class. And since this course was, after all, a philosophy course, I sought to insure that philosophical analysis and thought would be emphasized throughout.

Of course, one might still question whether any philosophy course can succeed on-line. In retrospect, I held some such assumption, however inchoate, when I began working on this project; it is, however, also the view of two professors who believe that computer technology can enhance some areas of learning:

Some fields...will never be suited to extensive computer mediation, especially those concerned with questions of meaning and value, of culture and philosophy [3].

In designing the course as I did I was attempting to rebut my own version of this claim. Thus, I tried to preserve many of the features of a traditional classroom: Students were required to buy and read books, write three essays, participate in (on-line) discussions, answer reading comprehension questions, and complete a final examination of two essay questions. In addition, I provided introductory and concluding lectures on each of Hobbes, Locke, and Rousseau, and I offered commentary on various portions of their texts. 


\section{THE DESIGN OF THE COURSE}

The basic pattern or design of the course is simple: Each philosopher is assigned to a database (Hobbes, Locke, Rousseau) wherein students can find lectures, discussion questions, and reading comprehension questions; an additional database (Introduction and Reference) includes the syllabus, a description of the course and course expectations, essays, grades, and student and faculty profiles. Along with these four databases, a fifth is used for storing outgoing and incoming e-mail.

After booting the computer a student would select the icon for Lotus Notes; at that point, the "workspace page" containing each of the five databases would appear just as it is reproduced below. (What is reproduced below is my version of the course, so the mail database has my name on it.)

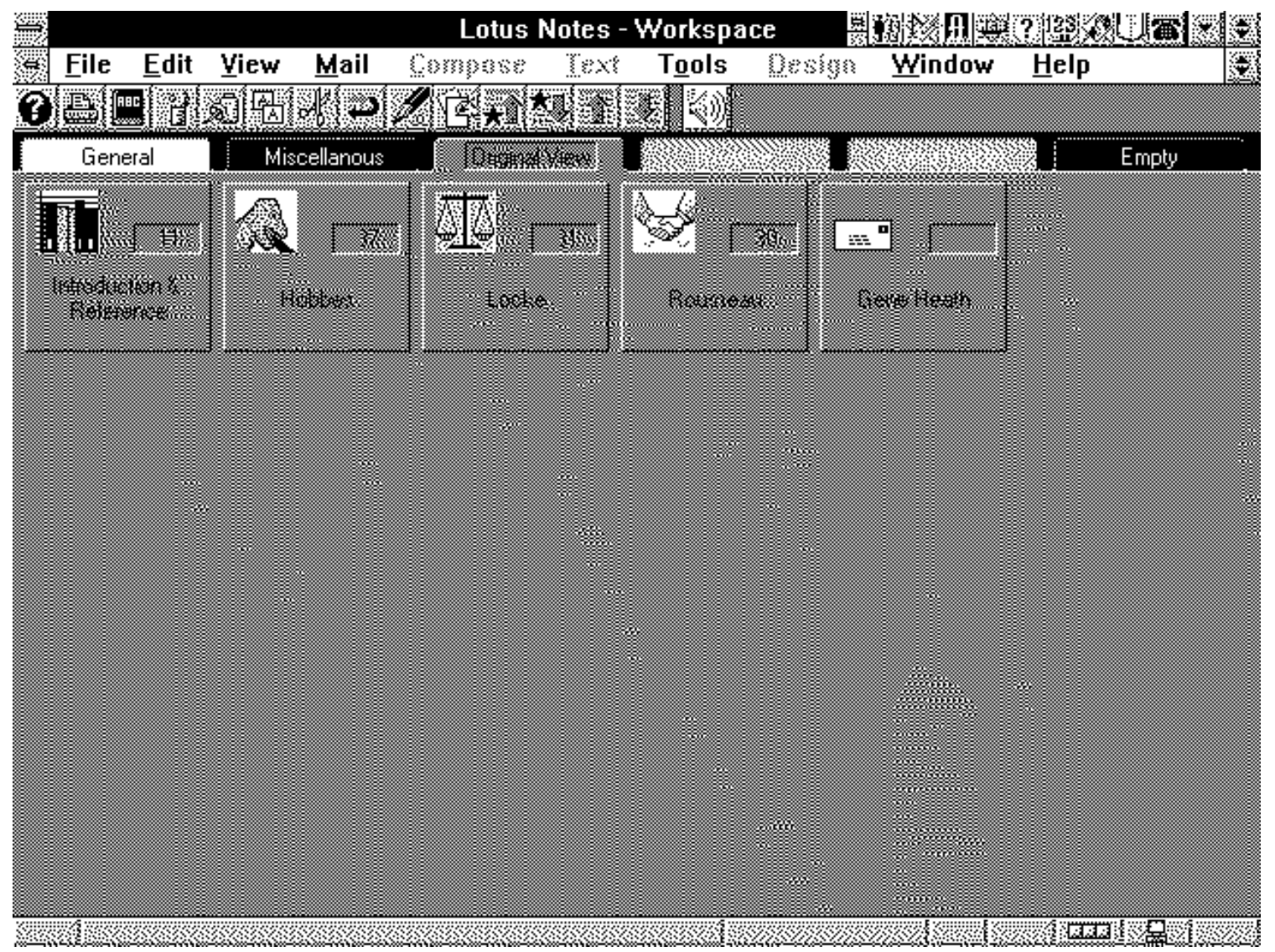

The first database on the left, Introduction and Reference, contains five subdivisions: (A) An introduction to the course; (B) Essay assignments (and submitted essays); (C) Teacher and student profiles; (D) Student Grades; and (E) a Bulletin Board. Reproduced below is a view of sections (A) and (B) of the database table of contents; each item listed under either (A) or (B) contains a document which can be either read on screen or printed onto paper. 


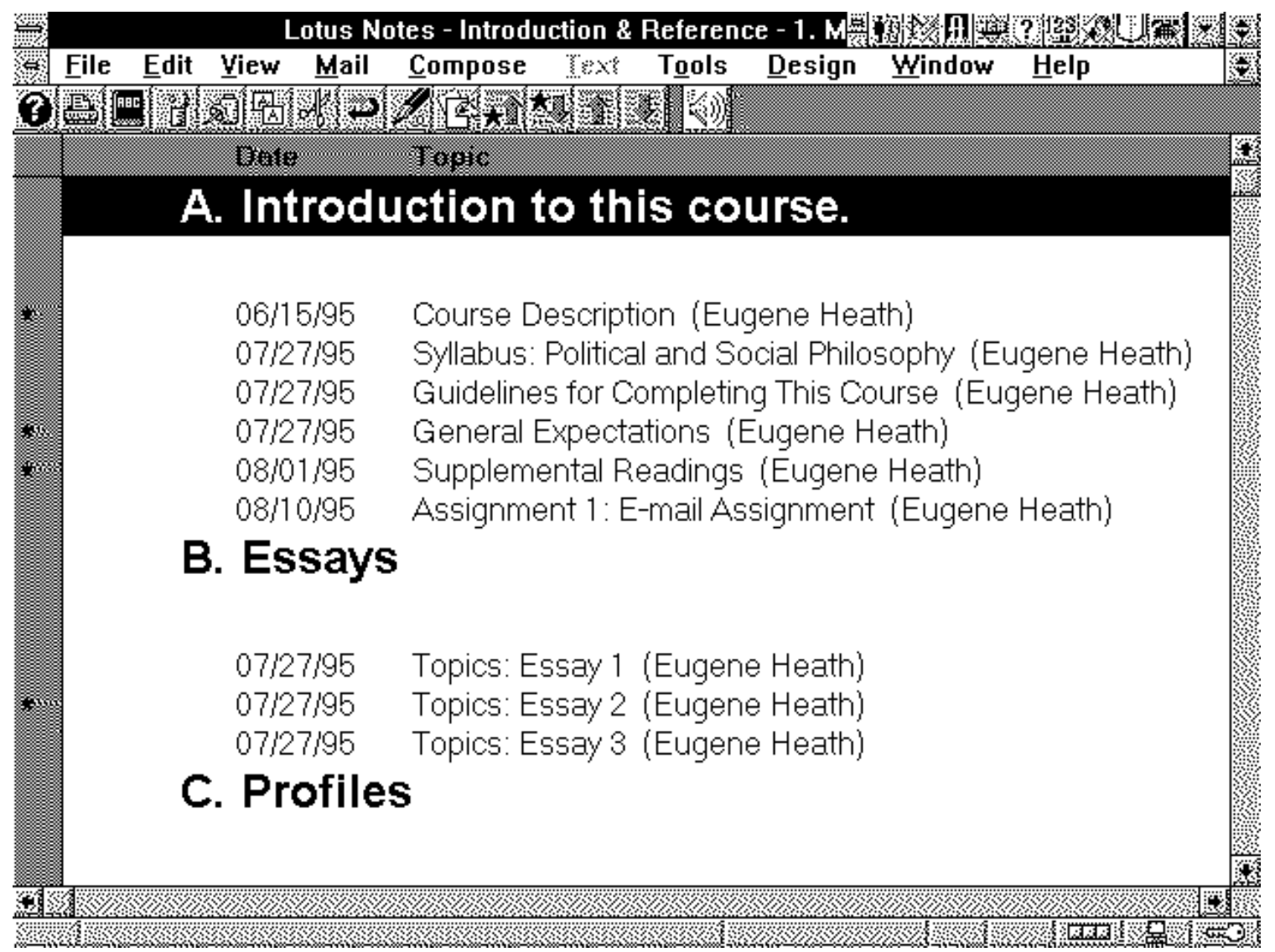

The syllabus for the course included the following schedule of readings:

Hobbes, Leviathan: Chapters 1-11, 13-18, 21, 24, 26, 29-30

Locke, Second Treatise of Government (all)

Rousseau, Discourse on the Origin and Foundation of Inequality Among Mankind (all);The Social Contract : Books I, II, III (chapters 1, 12-17), IV (chapters 1-3, 7-9) [4].

By selecting the document titled "Course Description" students would find an outline of the basic framework of the course. In the fourth and fifth sections of that document I outlined the format and requirements for the course; these sections are reproduced below.

\section{COURSE FORMAT}

1. Sequence There are five databases for this course: An introductory database, a database for each of the authors, and an e-mail database. The course will proceed, in sequence, through the three authors listed on the syllabus: Hobbes, Locke, and Rousseau.

2. Self-pacing Given that class discussion will proceed sequentially, the course is not wholly selfpaced. Nonetheless, it is still possible for you to participate in discussions while moving ahead through other topics in the course. 
3. Readings Each student will be expected to read all of the assigned readings and is required to buy the books; these can be purchased at Ariel Books in New Paltz or through the Empire State College Bookstore. In addition, all of the readings will be available on-line in an annotated--or "annotext"--format. The annotext offers commentary and questions which can help you to understand the rather difficult reading assignments. In addition, the annotext contains--for each set of readings--multiple choice review questions which can be used to gauge your understanding of significant ideas.

4. Introductions to the readings In each author database (Hobbes, Locke, Rousseau), you can access a general introductory lecture on the author's ideas and background. (There is also a concluding lecture for each author.) After reading this introduction (which should be printed for easier reading), you should then read the much briefer introduction located at the beginning of each annotext section. Having read these items, you should proceed to find a comfortable chair and begin to read the relevant section of the book itself. Read the book according to the sections noted on the syllabus! After reading a section of the book, you should return to the computer and begin working through the annotext.

5. Annotext In each author database, you will be able to review, from the computer screen, the selections of the text that you have previously read from the book. Available on screen is a set of annotations, indicated by an icon or button (either yellow or blue) appended to the text itself. Once you click on one of these, a new window opens on your screen and on this window you may read commentary, answer questions (for your annotext notebook), consider discussion questions, or (at the end of each section) complete a multiple choice review (or "self-test") of the section of text you have just completed. Your grade for the course will be based, in part, on your responses to annotext questions. (For further instructions on annotext, see the document in each author database: "Annotext: A Basic Introduction.")

6. Final exam This will be a timed essay exam. Students will be provided with a set of topics (e.g. ten) prior to the exam. You may then communicate with classmates concerning these topics. A subset of these topics (e.g. three) will be randomly chosen and rewritten as exam questions. Once you have accessed these questions (via the server) you will then have a limited amount of time in which to submit your responses to any two of these.

7. Office hours Regular office hours will be Monday through Thursday, 11:00-12:00. You may may reach me either on the phone or in my office. Of course, you may send me an e-mail at any time.

8. Bulletin Board Use the Bulletin Board, located in each database, to pose general questions or comments to the class. At times, I will also post announcements on the Bulletin Board. You should check this Board at least once a week.

9. Access to Your Documents In order to provide prompt technical assistance, it is necessary that the technical support personnel, at the Center for Learning and Technology, be able to view any document that you create in your course databases. Be aware that this is the case even if you use the PRIVATE SAVE option when exiting a document. This does not, of course, apply to email: All e-mail communications can be viewed only by the sender and receiver. 


\section{COURSE REQUIREMENTS}

Each student must complete all three sections (Hobbes, Locke, Rousseau) of the course. Completion of these sections will be monitored by the professor who will be able to determine how often a student has worked at the computer and whether that student is completing the selftests in the annotext documents. In addition, the professor will be an active participant in the online discussions.

1. Quality and Consistency of Discussion (15\%) Discussion questions are indicated, in the annotext, with a $\mathbf{D}$ icon. The total discussion grade will be composed of the average of three separate discussion grades each of which will be assessed upon the completion of each author (at the end of the 4th, 9th, and 14th week of class). You can gain access to your classmates' responses by opening the document (in each database) labeled "Discussion Questions."

2. Annotext notebook (15\%) Each time you respond to one of the reading comprehension questions (indicated by a $\mathbf{Q}$ icon in the annotext), your response can be sent to the professor; when you send your response to the professor the computer will automatically place your response into your own "Notebook of annotext questions" (there is a notebook in each of the author databases). A grade for your annotext responses will be given at the end of the semester.

3. Essays $\mathbf{( 5 0 \% )}$ ) There are three essays: A very short exposition (of one page) worth $10 \%$ and two five-page essays worth $20 \%$ each.

\section{Final Examination (20\%)}

As one can see, the set of assignments for the course mirror those which would be employed in most philosophy classes. In this way I sought to preserve both content and some opportunity for philosophical analysis. However, I also sought to take advantage of the medium of the computer; in order to do so, I considered this question: What might the computer provide that a classroom might not (so easily) offer? To answer that question I first considered that well-known problem of teaching: Underprepared students who find it difficult to understand any text of sustained thought or analysis [5]. Given the difficulties that students would have in understanding the readings, I decided to orient my course in such a way that students would have to engage the text in order to comprehend, analyze, and discuss. To do this, I decided to have all of the relevant reading material on-line and annotated [6]. The result is what was referred to above, in the course description, as "annotext".

I annotated the the works of Hobbes, Locke, and Rousseau by placing five types of icons or buttons--numbered and labeled--at selected places in the (on-line) texts; upon selecting any such icon the student could either read my commentary $(\mathbf{C}$ or $\mathbf{E})$, answer reading comprehension questions $(\mathbf{Q})$, respond to discussion questions $(\mathbf{D})$, or complete a multiple choice review quiz $(\mathbf{R})$. Pictured below is a reproduction of a screen from the Hobbes annotext (paragraph four of Hobbes' introduction to his Leviathan). 


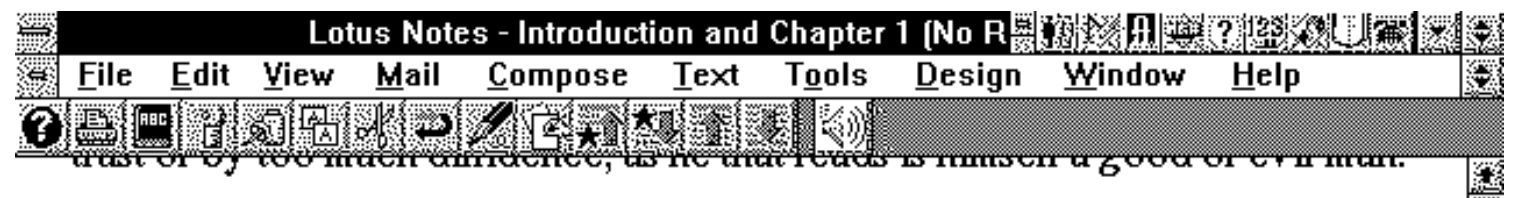

[4] But let one man read another by his actions never so perfectly, it serves him only with his acquaintance, which are but few. He that is to govern a whole nation must read in himself, not this, or that particular man; but mankind: which though it be hard to do, harder than to learn any language or science; yet, when I shall have set down my own reading orderly and perspicuously, the pains left another will be only to consider if he also find not the same in himself. For this kind of doctrine admitteth no other demonstration.

$8 \mathrm{C} 3$

(22.
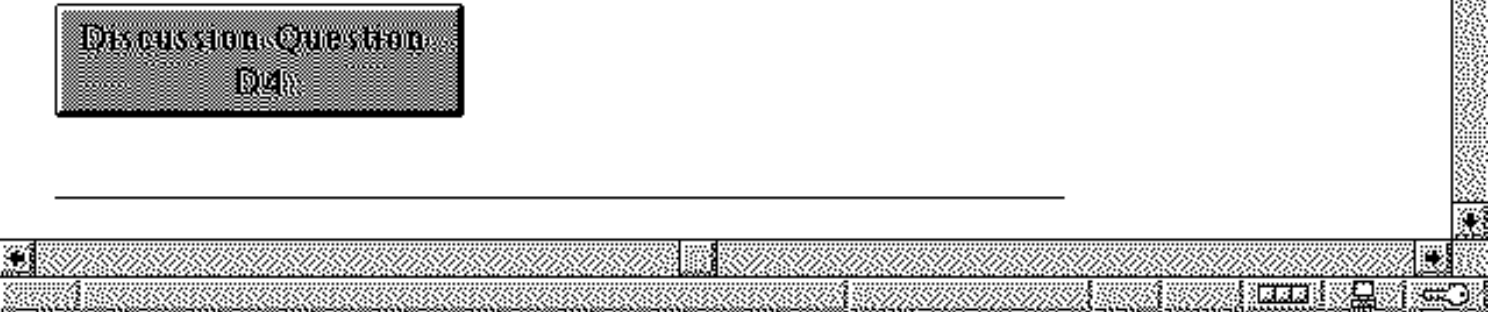

The reproductions that follow provide a glimpse of four of the five types of annotext, each of which is introduced by a summary statement.

$\mathbf{C}$ (Commentary) A $\mathbf{C}$ icon contains comments on the text itself and is specifically related to the general subject matter of the course. Below is a reproduction of a view of the sixth $\mathbf{C}$ icon in Hobbes' Leviathan; this icon appears at the end of paragraph five of chapter one. 


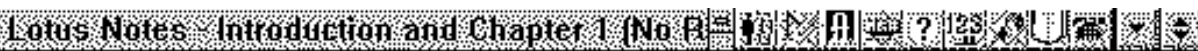

\begin{tabular}{|c|c|c|c|c|c|c|c|c|c|c|c|}
\hline 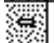 & File & Édit & View & Mail & Compose & Iext & Tools & Design & Window & Help & 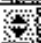 \\
\hline & 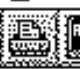 & 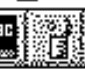 & 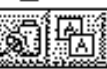 & 4 & 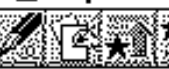 & 要 & 絗 & & & & \\
\hline
\end{tabular}

[5] But the philosophy schools, through all the universities of Christendom, grounded upon certain texts of Aristotle, teach another doctrine; and say, for

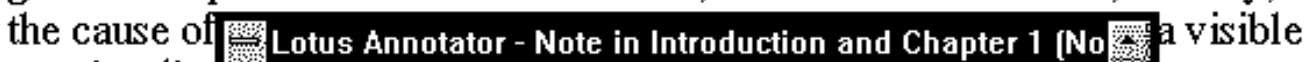

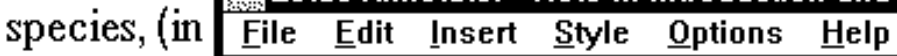
the receivin L6. This is but the first of Hobbes' criticisms of those that the thin who are not sufficiently attentive to a careful and aspect, or al precise use of language. Indeed, as we shall see very $\mathrm{Nay}$, for the shortly, Hobbes believes that one cannot have a true "science" of politics unless one begins one's sendeth fort deliberations with clear definitions of the terms that coming into one is to employ. disapprovin their office way what th of insignific<smiles>[C+]C1CCC2CCC12</smiles>
ig seen; fearing, lible earing. tood en; which, as eafter of by the equency

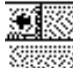

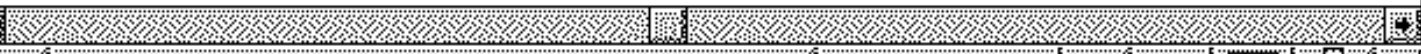

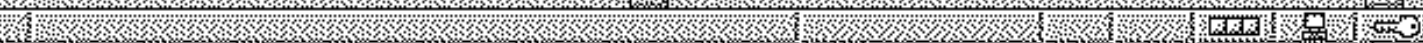

E (Commentary for enrichment) An $\mathbf{E}$ icon contains comments that are not essential to understanding the general topics of this course, though they are helpful in understanding the text. (No reproduction is offered.)

Q (Questions, or commentary with questions) A $\mathbf{Q}$ button contains questions (and, in some cases, accompanying commentary) intended to guide the student's understanding of the text. The student's response to a $\mathbf{Q}$ insert is sent (i) to the professor and (ii) to a division of the (student's) relevant database called, "Notebook of Annotext Questions." The student's responses to these questions are periodically reviewed and commented on by the professor, but a grade for all $\mathbf{Q}$ questions is given only at the end of the semester. Reproduced below is a $\mathbf{Q}$ question which appears immediately after paragraph 47 of chapter five of Locke's Second Treatise. (Note that the first row of buttons allows the student to divide the screen in half so as to view, at the same time, the actual text and the question. The second row of buttons permits the student either to save an answer without allowing the professor access or to send the answer to the professor and to the student's document called, "Notebook of annotext questions.") 


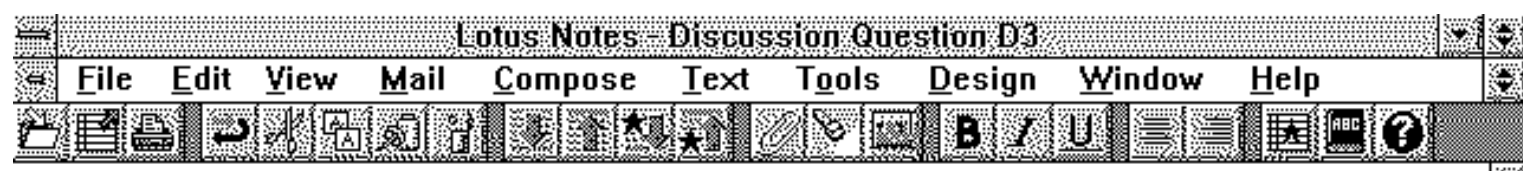

\section{Discussion Question D3}

What does Roussean mean when he writes, "the savage lives in himself; the man accustomed to the ways of society is always outside himself and knows how to live only in the opinions of others"? Is Rousseau correct? If so, in what sense?

Text of Answer: / I

Wert PreW6us Drobument

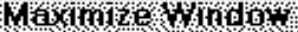

IMPORTANT! Use buttons below to save or exit.
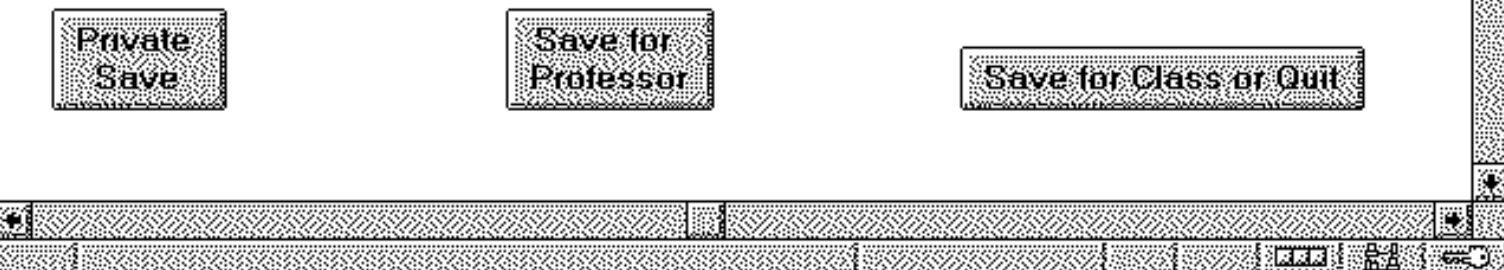

$\mathbf{R}$ (Review questions) An $\mathbf{R}$ button contains a set of multiple choice questions which the student can use to gauge his or her comprehension of a selected segment of the text. $\mathbf{R}$ questions receive no grade. One screen of a review quiz appears below; this quiz could be found, in the annotext, as the very last icon in the very last section of the assigned reading of Leviathan. (Most review quizzes contained about ten questions.) 


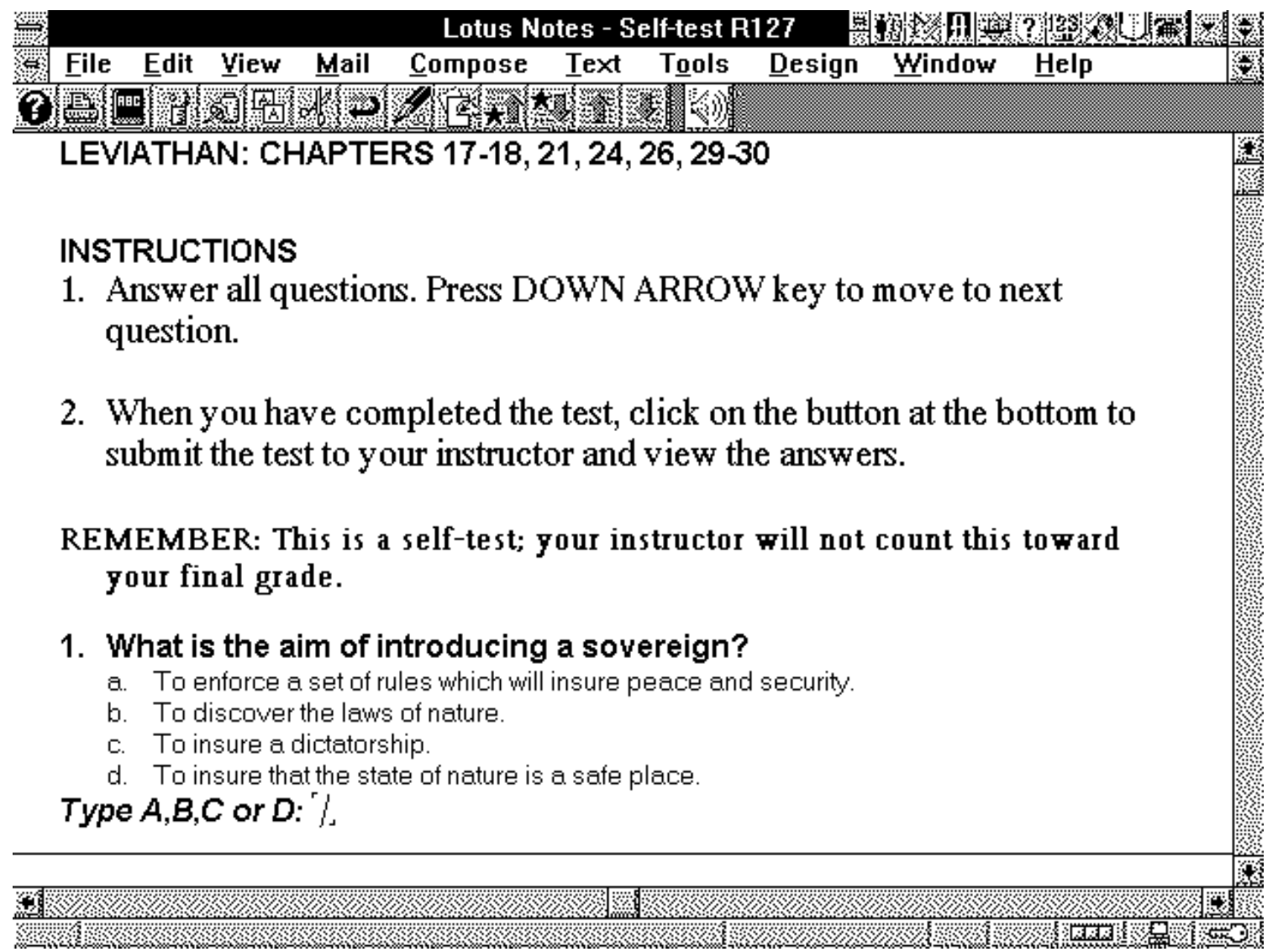

Below is a table showing the frequency of annotations for each of Hobbes, Locke and Rousseau.

\begin{tabular}{|l|l|l|l|l|l|}
\hline & C & E & Q & D & R \\
\hline Hobbes & 54 & 02 & 60 & 12 & 04 \\
\hline Locke & 50 & 01 & 55 & 11 & 04 \\
\hline Rousseau [8] & 23 & 00 & 24 & 04 & 01 \\
\hline
\end{tabular}

The basic structure and sequence of the course can now be summarized. After examining the various documents in the Introduction and Reference database, a student would proceed to the Hobbes database. There the student would find my introductory lectures which could first be printed and then taken to a table or armchair for study. Having examined these lectures, the student would then read the first one or two chapters of Leviathan. Once these chapters were read the student could return to the computer and scroll through the text, perhaps rereading, from the screen, certain portions of Hobbes' work [9]. When the student would come upon an annotext button $(\mathbf{C}, \mathbf{E}, \mathbf{D}, \mathbf{Q}$, or $\mathbf{R})$, the student would select the button and proceed, for example, to read my commentary $(\mathbf{C})$, answer a reading comprehension question $(\mathbf{Q})$, or respond to a discussion question (D). At the end of selected portions of the text, the student could test his comprehension by taking the multiple choice review test $(\mathbf{R})$. As the course would proceed a student would continue reading and answering $\mathbf{Q}$ and $\mathbf{D}$ questions; in addition, the student would reply to or comment on other students' responses to $\mathbf{D}$ questions. This same sequence of study and activity would be repeated in each of the databases for Locke and Rousseau. In addition to annotext, students were also required to write three essays. These were submitted on-line and returned to the students on-line; comments and evaluations were inserted into the essays using boldface script 
within square brackets. All grades were posted and calculated in a private document available only to the student.

In order to provide a sense of the nature of the on-line discussion, I reproduce below a (partial) view, from the Locke database, of the titles of the responses and comments to discussion question D3 [10]. This question, which appears at the end of paragraph 43, chapter 5, of Locke's Second Treatise, offers the following comments and questions:

In the previous few paragraphs Locke has reiterated his view that labor bestows value upon land. The "value" to which he has been referring is to be measured in terms of the benefits which the combination of labor and land bring to human beings. Does this mean that land has value only in so far as it is useful to human beings? Is there no intrinsic value to nature itself? After all, in paragraph 43 Locke refers to "natural intrinsic value"; is this intrinsic value to be defined only in terms of the land's potential for human use?

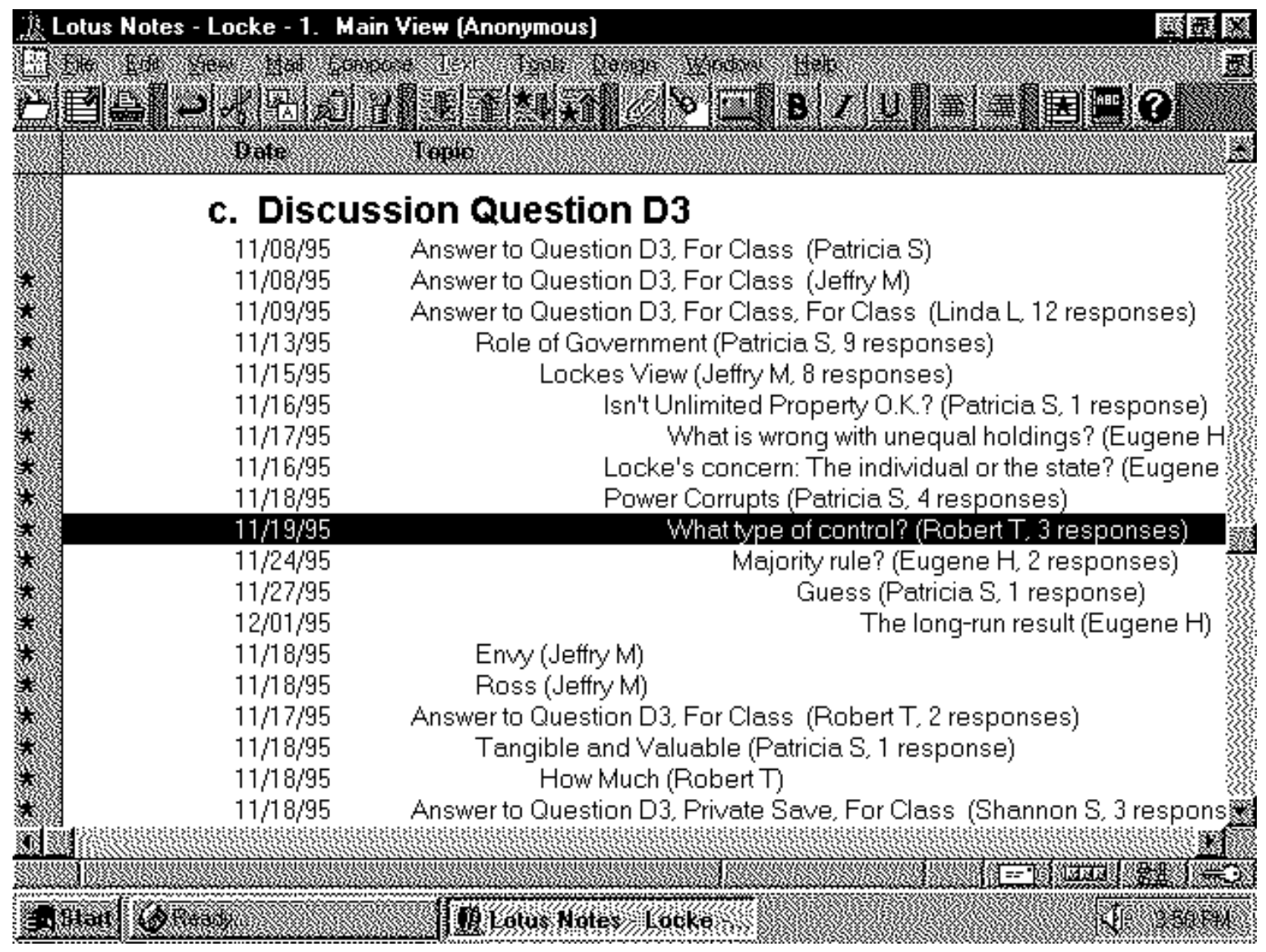

\section{COURSE ASSESSMENT}

The course that I have described requires significant amounts of time for development. During the summer of 1995 I spent over two months working full-time to develop the course. In addition to my efforts, Larry Greenberg, of the Center for Learning and Technology at Empire State College, provided invaluable technical assistance and programmed the course for the computer. 
Compared to the amount of effort required in development, the time required to teach the course was minimal: Although I did check in on the course at least once a day, the average amount of time required was but thirty to forty-five minutes per day. (On the issue of time, it is important to recall that there were but eight students who finished the course.) In a typical period of thirty or so minutes, I could respond to discussion questions and offer comments on the students' progress through the $\mathbf{Q}$ questions of annotext. Of course, additional amounts of time were required to grade essays, but given that reading and writing assignments, lectures, and annotext comments, questions, and quizzes had been completed at the beginning of the semester, the course rather seemed to run itself.

It is my judgment that any on-line course requires a clear structure, set patterns of activities, recognized deadlines, and a simple set of basic computer executions. That said, such courses are not for everyone: The SLN is, as mentioned above, intended for working adults rather than traditional-age college students. If the successful completion of an on-line course involves the completion of all assignments (discussion and annotext questions, essays, and the final exam) with a cumulative grade of at least a "B-" (a grade which would indicate that the student had performed well though not excellently), then it would also seem to be true that many adults possess some of the qualities necessary for on-line success: Self-discipline, strong motivation, and good writing skills. In my course, the successful student required approximately ten hours of work (off- and on-line) per week. Although this equates rather closely with what I would expect of a traditional three hour course, the institutional setting of a classroom offers a set of motivational supports that is missing from a computer course. (After all, a computer--quietly resting on a desk in another room--is much easier to ignore than a classroom or a professor who expects to see you at a certain hour on certain days.) Thus, only those students who were highly motivated and self-disciplined seemed to succeed in my course. Typically, these were the nontraditional students who were working and had a family!

Of the eight students who finished the course, most recognized the importance of high motivation but welcomed the course for its convenience and flexibility. In addition, many of these students evaluated quite highly the interventions of the professor--through my prepared commentary $(\mathbf{C})$, my periodic review of the students' responses to $\mathbf{Q}$ questions, and my participation in the on-line discussions (D). In addition, students appreciated being able to read the (D) responses of other students and judged the availability of the other students' ideas to be helpful in their comprehension and analysis of the text.

Even if the students in an on-line course possess strong motivation and good writing skills, there is still the matter of insuring that enough students are participating, thoughtfully, in the on-line (D) discussions. Most of the students' initial responses to a discussion question were of the order of one to three paragraphs; their comments on the responses of their classmates were typically shorter. Not all students did participate, thoughtfully or no, in a regular fashion: Some worked feverishly but irregularly; others worked less intensively but more consistently. The overall outcome was that some students did not participate as fully and evenly as others. For those who did participate evenly and intensively, the lack of participation by other students was regarded negatively. Indeed, as the semester wore on, I found that all students were participating at a declining rate: Although students continued to contribute their initial responses to the discussion questions, they also tended to pose fewer and fewer comments on the responses of their classmates.

That said, I evaluate quite positively my overall experience in teaching this course. Indeed, although there are those who regard on-line courses less as opportunities for teaching than for "facilitating" or "managing"[11]. I could not understood my role as one of mere management. 
And thus, for this opportunity to teach in a new and challenging context, and to consider issues of pedagogy in a practical and immediate manner, this course has proved valuable. And for those students of mine who did persevere to the end of the semester, it is my impression--and it is nothing more than that!--that they read important books, discussed significant ideas, and acquired some facility in analyzing, and reflecting on, the foundational issues of modern political and social thought. Of course, it could be argued that highly motivated and self-disciplined students could take advantage of and succeed in almost any environment. So if on-line courses effectively filter out the poorly motivated or weakly self-disciplined, then it may be no surprise that such students learn effectively: They would have learned effectively anywhere!

\section{A MODIFIED SCEPTICISM}

That I view my on-line course--at least, according to some common-sense and traditional criteria--as a success does not mean that I view computer-mediated education, especially in the liberal arts disciplines, to be the equivalent of the classroom (or, more specifically, the small classroom of, say, twenty-five students). My initial skepticism about such courses has been modified, but there are, at least in these early stages of the development of educational technology, reasons for remaining wary, especially in light of the ambitious and glowing accounts that are presented by some of the defenders of computer-mediated education. There are various reasons to be cautious, some of them stem from features (of on-line courses) which are intrinsic to the medium, others from the contingent ways in which the medium is (or might be) used. What these considerations indicate, at least at this early stage, is not that on-line education--even for such disciplines as philosophy--has no place in the serious college or university, but that the place that it does have should probably be a subordinate one: On-line education should be viewed as a surrogate for the face-to-face encounter between teacher and student [12].

I shall first mention some of my reservations which, for lack of a more precise term, I call "contingent": These concerns arise either from how the medium may be used or from how (some) advocates defend the medium. For example, even though the advocates of on-line education are aware of problems of motivation and pacing (which themselves may be contingencies that are capable of being overridden in a variety of ways, including the non-technological), few seem to be aware of the most fundamental issue: Whether the technology is allowed to drive the content and direction of a course. As an example of how this issue can be ignored, I can cite, from two books devoted to on-line education, the advice of those who contend that any professor teaching (or developing) an on-line course should avoid posting lectures, or written materials, that are much longer than a computer screen ! [13] Such an admonition does not, however, seem intrinsic to the medium nor does it seem productive of real learning: To state the obvious, a well-written lecture can provide background, perspective, and insights that could not otherwise be easily obtained but are essential to understanding and reflecting on a topic, an argument, or a text. (Recall, in this regard, the texts for my on-line course: How is a student to understand Hobbes' Leviathan without understanding the intellectual background and context of that work? And how is the student to comprehend that background and context unless it is presented in some organized fashion by the professor?) Why, then, should the on-line lecture be avoided? After all, a student need not read the lecture off of the screen but can print it out and read it as a book would be read. Perhaps the printed lecture does not take full advantage of the computer--precisely so! However, why assume that an on-line course must require that all course activities occur at the keyboard and screen? If we do make some such assumption, then we will very quickly reduce philosophical, literary, and historical ideas to the level of sound-bites and bumper stickers. 
If on-line courses are ever to deliver a sound liberal arts education; if, that is, they are to deliver something more than information and something more substantial than a forum for brief comments, then an important distinction must be recognized: It is one thing for a computer to deliver a course (to someone who might not otherwise be able to attend a college or university) and it is another thing for the computer to be the very focal point and process by which the course is conducted. As a delivery mechanism, the computer offers flexibility and convenience; however, if some feature unique to the computer serves as the focal process of the course, then it is all too easy for the technology to dominate the content: Learning is limited to what can appear on the screen, careful reading is replaced by colorful graphics, and thought and reflection is subordinated to the retrieval of information and the composition of brief comments. If one considers a technological process to be the source of all (or most) learning, then one will devalue lectures, dismiss off-line reading and reflection, undervalue formal writing, and celebrate on-line participation, communication, and collaboration.

Indeed, according to many advocates of on-line education, one of the more noteworthy features of on-line software (or "groupware") is that it provides structures--such as those which I relied on for my own course discussions--in which students and faculty can work or conference together and in which the various contributions of the participants can be ordered and structured in distinct graphical modes. Although such structures have their advantages, it is not obvious that collaborative learning, or on-line conferences and discussions, should be understood to be essential (or even primary) components of on-line education [14]. That is not to say that on-line discussions have no place; of course they do! Nor do I, having employed such discussions, wish to deny that there are some advantages to on-line communication or conferencing: Students have the opportunity of posing questions to the professor whenever they want, and they may communicate with one another without the social barriers of race, class, or status. (Indeed, most of my students evaluated the on-line discussions quite favorably!) However, the on-line conference is but a technological system and as such it is no guarantee of learning [15], indeed, the danger is that on-line participation and communication may, because of its verifiability, become the sought after, and primary, outcome of such courses rather than the more difficult to measure outcome of learning [16].

There is, however, a more fundamental concern: Is the on-line conference (or team or group discussion) an equivalent of the focused and engaged discussion (and thought) that can occur in the face-to-face encounters in the classroom? Consider, in this regard, that when one comments on the on-line statement of another, one may not be responding to the other as a teacher, a pupil, or a classmate, so much as one is performing some quick operation on a disembodied piece of text, a text that may not really be expressive of what the other person meant. Indeed, in a classroom (and elsewhere), one of the most important philosophical questions is that of meaning: "What do you mean by '___ '?" To pose this question on-line is rather inefficient: For this sort of question often presupposes some immediacy of context; such immediacy is obviously helpful to the individual who must answer that question and who must attempt to discover some unexpressed but intended meaning. However, if this question is posed on-line, then significant time may elapse between the original statement and the question, or between the question and the response, thus extending what might otherwise have been a fruitful five-minute discussion (in the classroom or office) into a one-week expanse of misplaced context and unrecalled intention.

Of course, if topics or questions for discussion are sufficiently deep and sturdy then the responses may be developed and thoughtful; and if the professor moderates the discussion carefully, emphasizing, from the day of commencement, the importance of clear expression, then students may endeavor to write responses that are more than shreds of thought and clearer than ventilated opinion. Nonetheless, the exchange of comments via computer may raise questions that are not 
merely contingent but intrinsic to the medium; to these I will turn only after noting another contingent issue, one that is also related to the matter of computer conferences.

Many advocates of computer education, having lauded the idea of conferencing and collaboration, also praise what they see as the egalitarianism that is introduced between teacher and student: "The educator becomes less an authority figure and more of a resource and facilitator for the learning activities of the group" [17]. Another advocate, having first noted that "computer conferencing may contribute to less authoritarian concepts of learning and teaching," contends: "the most important function of the teacher in computer-mediated distance teaching will be to keep track of the processes taking place and developing throughout a course" [18]. The advocates of on-line education, having assumed that some form of collaborative learning is the paradigm for computer courses, also assume that such learning will foster an egalitarian relation between teacher and student. However, even if there is a sense in which on-line education, in whatever form, diminishes somewhat the psychological distance between teacher and student, that does not seem to entail that the professor must relinquish, by right or by fact, academic authority, serving instead as a manager or facilitator. Just as we should not assume (a) that since the computer permits on-line conferences, these should be the focal point of any on-line course, neither should we think (b) that the teacher who participates in such conferences should forswear any claim to knowledge, experience, or scholarly authority. To do so is to exalt managerial technique at the expense of pedagogical and ethical practice [19].

The considerations limned above, which focus on particular methodologies, do not seem to address any feature of on-line education that is intrinsic to the technology. However, it would seem that, apart from issues of job security, the technological aspect of such education is the feature that worries most professors of the liberal arts. It is not altogether simple to delineate how the technology may weaken or diminish the study of these subjects, but one obvious matter for concern is that on-line education reduces all communication to written propositions. The difficulty here is not that each set of instructions, each comment, lecture, or evaluation--unlike a professor's notes for classroom teaching--must not leave unexpressed any relevant item; rather, the real issue is whether teaching and learning can be reduced to written propositions. I shall address this question by discussing three related topics: The professor as a cause of thought; the profession of teaching as a practice; and the college as a place.

In the first instance, it might be argued that the written word, whether on screen or paper, is not as compelling as the person or the voice. A set of on-line course documents, or a database for online conferencing, may offer opportunities for thought and reflection, but these documents may not cause reflection, at least not in the same nuanced manner as a skilled teacher causes one to think and reflect. Good teaching involves an element of performance, of casting oneself into the role of one who is not merely a voice for some thought, idea, argument, or event but who is also capable of causing thought and reflection in the listener (the learner). A professor's lines will change at every class (even if one has taught the course several times), and to render those lines effective (in the sense of effecting thought) one must have some awareness of one's audience.

This awareness is not merely an awareness of facts about the audience (so-and-so dislikes Plato, is active in student government, is unhappy, and so forth) but an awareness of that audience's attentiveness, comprehension, seriousness, and interest [20]. Without such awareness, the classroom professor is merely speaking, reading, or explaining, all of which could be done in a room with no one present. And what is the professor doing when engaged in on-line teaching? The on-line awareness of the professor is limited to whatever facts may be gleaned from some online profile of students or from the professor's own evaluation of the student's written work; however, and in my brief experience, none of this matches the immediacy or efficiency of direct 
face-to-face, awareness. In its absence, there is little room for the unarticulated understanding, the spontaneous insight, or the developing sympathy that can arise between teacher and learner.

The matter of a professor's awareness leads to a second issue, for such awareness is but an instance of what might be called the "pedagogical perception of particulars." Such perception is itself a condition of judgment and know how, neither of which can be reduced to rules or systems but both of which are essential components of the practice of teaching. Indeed, if teaching is a practice involving unarticulated judgment and know how, then it is not all that obvious how teaching, in its most realized state, can be converted to the more restrictive confines of on-line education in which learning activities must be clear and discrete (viz. those activities which occur on-line, within the purview of the professor) and all communication must be reduced to disembodied propositions.

The practice of teaching involves, of course, more than judgment or know how: It is also exemplary of attitudes, dispositions, emotions, and commitments, none of which are easily conveyed through written propositions. The attitude and demeanor of a professor can not only serve to communicate the importance of a subject but also to exemplify qualities of mind and character. If, following Aristotle, such qualities are born of experience within a rightly ordered community, then it is not at all clear that the metaphorical community of cyberspace provides the proper setting. For within such a metaphorical community, there is little opportunity for the student to observe the qualities of judgment, commitment, and intellectual awareness; as Michael Oakeshott so effectively puts it, any such quality or ability is taught by example:

It is implanted unobtrusively in the manner in which information is conveyed, in a tone of voice, in the gesture which accompanies instruction, in asides and oblique utterances, and by example. For 'teaching by example', which is sometimes dismissed as an inferior sort of teaching, generating inflexible knowledge because the rules of what is known remain concealed, is emancipating the pupil from the half-utterances of rules by making him aware of a concrete situation. In imitating the example he acquires not merely a model for the particular occasion, but the disposition to recognize everything as an occasion [21].

Finally, of course, the place for the inculcation of such intellectual qualities is the school, the college, or the university [22]. A (physical) place devoted to learning, study, and research, a place to which one must go at certain hours, may prove inconvenient to some, but its very inconvenience is also its signal importance: Some things have to be set aside if one is to engage, focus, and commit oneself to learning. Though this is one consequence of place, it also implies the seriousness of education. That the computer is convenient because its courses occur in no real space or time easily translates into the view that one need not engage when one doesn't want to, that one need not set aside certain activities for the sake of learning, and that one may, simply, turn off the machine if something is too difficult; in sum: learning is no more important than anything else.

Perhaps, in fact, and lamentably, it has become less important than many other things, whether these be earning money, working, or, under the guise of some of the advocates of on-line education, some shallow form of egalitarianism or some trivializing effort to democratize learning. One can only wonder if the very decline of learning, along with the decline of the idea of a college, has set the stage for those who wish to claim that on-line education is "equal or superior to" traditional education [23]. Although I believe that the rudiments of a particular subject can be attained through an on-line course, and although some on-line courses may be preferable to some classroom courses, my initial scepticism has not been eliminated--it has only been modified. Perhaps on-line education has a place, but it is a subordinate one; on-line 
education is best viewed, at least under current technology, as a surrogate: The best education occurs between teacher and student.

\section{NOTES}

1. The phrase "virtual classroom" is taken from Starr Roxanne Hiltz, The Virtual Classroom: Learning Without Limits via Computer Networks (Norwood, NJ: Ablex Publishing, 1994).

2. The requirements for Macintosh users differ slightly. Some of these Computer specifications will be revised in 1997 when the SUNY Learning Network is placed onto the World Wide Web.

3. William F. Massy and Robert Zemsky, "Information Technology and Academic Productivity," Educom Review 31 (January/February, 1996): 13. The view of Massy and Zemsky might be compared to the more ambitious outlook of Linda Harasim, Starr Roxanne Hiltz, Lucio Teles, and Murray Turoff in their book, Learning Networks: A Field Guide to Teaching and Learning Online (Cambridge: MIT Press, 1995). For example, they write "The real question...is not whether a course can be done online but what is the best media mix to achieve the goals of the course..." (p. 24).

4. It should be noted that the class did not complete the syllabus: We did not have sufficient time to read Rousseau's Social Contract. This occurred for two reasons: This course was one of the first of the SUNY Learning Network courses to be offered and due to unforeseen difficulties in setting up each student's computer, the entire class was not ready to commence the course until ten days into the semester; secondly, as the semester wore on, with the class participating less actively then I would have wished, I postponed several deadlines, thus making it impossible to complete the syllabus. That said, it should also be noted that when I last taught this syllabus in the classroom (Sprint 1995) we were unable to complete The Social Contract!

5. I once made the mistake (?) of telling my students that in reading an assignment they should first insure that "they do not lose the forest for the trees." Out of insight or malice, I then asked the class what is meant by the expression "losing the forest for the trees." No one knew, for none of them had ever heard such an expression.

6. The relevant sections from Hobbes and Locke were downloaded from sites (within the public domain) on the Internet: http://ccwf.cc.utexas.edu/ thurmy/Philosophy/Hobbes-Leviathan and http://www.jim.com/jamesd/2ndtreat.htm. The relevant sections from Rousseau, scanned into the Lotus Notes course documents were taken form Rousseau: The Basic Political Writings, translated by Donald A. Cress (Indianapolis: Hackett Publishing, 1987). Permission to scan the portions of this text was obtained at a reasonable cost from Hackett Publishing.

7. As can be seen form the reproduction, each $\mathrm{D}$ question also allows the student to send a response only to me, the professor. However it was only at the beginning of the semester that a few students, anxious abut the quality of their responses, elected this option.

8. The numbers listed for Rousseau do not include the buttons for The Social Contract, which, as indicated in note 4 above, was not read.

9. I do not know if every student followed this path of activity: Specifically, I do not know if each student first read the book and then proceeded to the annotext or if some students simply ignored the book and answered the questions in the annotext. If some students did opt for the latter maneuver, the sheer frequency of the annotext buttons would have forced then to read quite a bit of text that they might have thought they could avoid.

10. The view of the screen, reproduced below, has been altered in order to protect the privacy of the students enrolled in the course: The surnames of all participants have been deleted from the reproduction.

11. "The educator becomes less an authority figure and more a resource and facilitator for the learning activities of the group." Harasim, et al, Learning Networks, p. 31; "[T] he lecturer must cease to be a controller of knowledge, and must become a manager of learning." Roger Martles, "Videodiscs and the Politics of Knowledge," in David S. Miall, ed., Humanities and the Computer: New Directions (Oxford: Clarendon Press, 1990), p. 42.

12. In the discussion that follows, especially regarding the intrinsic considerations, my point is not to claim that on-line education is inferior to education within any small classroom: Obviously, some classroom education could be so poor, that almost any on-line course would be an improvement. My point is 
more mundane: Are there features of on-line courses which, all things equal, provide reason for caution?

13. Hiltz, The Virtual Classroom, p. 86; and Harasim, et al, Learning Networks, pp. 25, 178,191.

14. "The fundamental characteristic of network learning is the premise of collaborative approaches to learning. Networks are group communication environments that augment social connectivity." Harasim, et al, Learning Networks, pp. 274-5.

15. Others disagree: "Students actively present ideas and respond to one another's formulations, a process which contributes to facilitating higher developmental levels of understanding." Harasim, "On-Line Education: A New Domain," in Mason Kaye, eds., Mindweave: Communication, Computers and Distance Education (Oxford: Pergamon Press, 1989), P. 72, 55. "When teachers and students engage in cooperative learning activities mediated by computer networking, the power and speed of human learning is extended by their collective knowledge and rich set of experiences." Margaret Riel, "Global Education Through Learning Circles," in Harasim, ed., Global Networks: Computers and International Communications (Cambridge: MIT Press, 1993), p. 222.

16. "The sociability of conferencing resembles that of sports or games.... We can say that playing at computer conferencing consists in making moves that keep others playing. The goal is to prolong the game and to avoid making the last move." Andrew Feenberg, "The Written World: On the Theory and Practice of Computer Conferencing," in Mason and Kaye, eds., Mindweave, p. 27.

17. Harasim, et al, Learning Networks, p. 31.

18. Soren Nipper, "Third Generation Distance Learning and Computer Conferencing," in Mason and Kaye, eds., Mindweave, pp. 71, 72.

19. Just as Mill regarded his own era as a time of transition, perhaps we should consider whether ours is a period of technological change and intellectual division in which individuals will strain to attach popular political nostrums to their own technological interests. With regard to his own era, Mill writes, "in all other conditions of mankind, the uninstructed have faith in the instructed. In any age of transition, the divisions among the instructed nullify their authority, and the instructed lose their faith in them. The multitude are without a guide; and society is exposed to all the errors and dangers which are to be expected when persons who have never studied any branch of knowledge comprehensively and as a whole attempt to judge for themselves upon particular parts of it." John Stuart Mill, "The Spirit of the Age," in Essays on Politics and Culture, ed. Gertrude Himmelfarb (Garden City, NY: Doubleday, 1963), pp. 8-9.

20. Apparently, this was true even of Kant, at least according to Somerset Maugham: "It was his custom to fix his eyes on a student who sat close to him and judge by the look on his face whether or not he understood what he said." "Reflections on a Certain Book," in The Vagrant Mood (Garden City, NY: Doubleday, 1953), pp. 167-168.

21. "Learning and Teaching," in The Voice of Liberal Learning: Michael Oakeshott on Education, ed. Timothy Fuller (New Haven: Yale University Press, 1989), pp. 61-62.Those who are acquainted with Oakeshott's essays on education will recognize their influence on much of what I've written concerning the practice of teaching.

22. The importance of a school as a place is also emphasized by Oakeshott. See, for example, "Education: the Engagement and Its Frustration, “ in The Voice of Liberal Learning, esp. pp. 68-70.

23. "The traditional classroom learning situation is generally assumed to be the best to support learning, with other learning modes perhaps perceived as less effective. There is no evidence to support this assumption. In fact, quite the opposite is true: Online environments facilitate learning outcomes that are equal or superior to those generated in the face-to-face situation." Harasim, et al, Learning Networks, p. 27.

Eugene F. Heath, Dept. of Philosophy, SUNY 1000 JFT, New Paltz, NY 12561 